\title{
НБИКС-ТЕХНОЛОГИИ - КОНЦЕПЦИЯ РЕФОРМАЦИИ ИЛИ ФУНДАМЕНТ БУДУЩЕГО ТЕХНОЛОГИЧЕСКОГО ПРОРЫВА?
}

\section{NBICS TECHNOLOGIES - CONCEPT OF REFORMATION OR FOUNDATION OF THE FUTURE TECHNOLOGICAL BREAKTHROUGH?}

Г.Е.Кричевский, д.т.н., проф., эксперт ЮНЕСКО, Заспуженный деятель науки РФ, вице-президент Нанотехнологического общества России (ORCID: 0000-0002-6970-7798) / gek20003@gmail.com G.E.Krichevsky*, Doct. of Sci. (Technical), Prof., Expert of UNESCO, Honoured Scientist of Russia, vice-president of Nanotechnological Society of Russia

DOI: 10.22184/1993-8578.2021.14.2.88.93

Получено: 05.05.2021г.

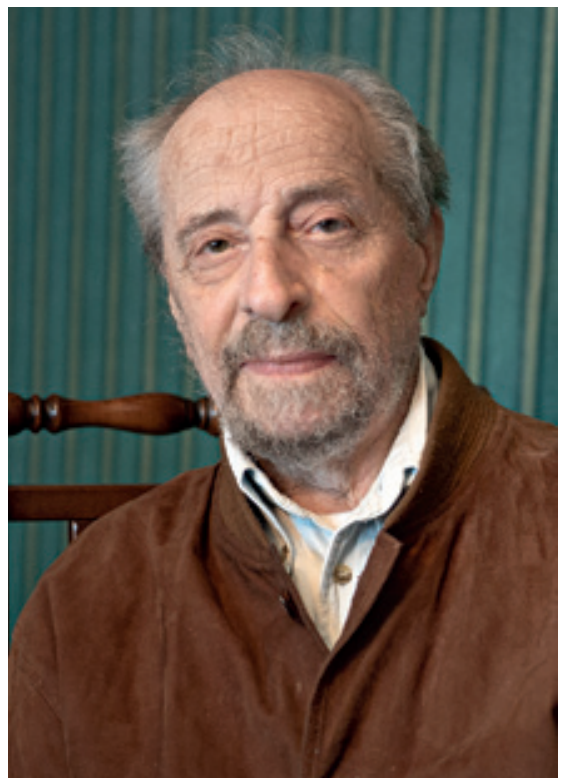

Прогресс человечества в области производства неминуемо приводит к пониманию того, что лучшим учителем является Природа. Пройдя путь от варварского, губительного для природы и климата низшего технологического уклада, увидев и ощутив его последствия, пережив ряд катастроф, почувствовав угрозы самого существования нашей планеты и человечества как такового, мы постепенно приходим к осознанию необходимости перехода к природоподобным технологиям, тщательному и выверенному пониманию последствий создания новых производств. Доктор технических наук, профессор, Заслуженный деятель науки Российской Федерации, эксперт ЮНЕСКО и вице-президент Нанотехнологического общества России Герман Евсеевич Кричевский размышляет о будущем образования, науки и промышленности на базе развития своей концепции о нано-, био-, инфо-, когно- и социотехнологиях, делится воспоминаниями и рассказывает о своих научных исследованиях и опыте внедрения новых технологий.

The progress of humanity in production sector inevitably leads to an understanding that the Nature is the best teacher. Having come a long way the lowest technological layer, barbarous and destructive for the Nature and climate, seeing and feeling its consequences, surviving a number of disasters, feeling a threat to the very existence of our planet and humanity as such, we are gradually coming to awareness of the need to move to the environmentally-like technologies, careful and verified understanding of the consequences of the newly created industries. We are talking to German Evseevich Krichevsky, Doctor of Technical Sciences, Professor, Honored Worker of Science of the Russian Federation, Expert of UNESCO and Vice-President of the Nanotechnology Society of Russia. He reflected on the future of education, science and industry developing his own concept of nano, bio, info, cognic and sociotechnologies, shares his memories and tells about his research and experience in introducing new technologies. 
Герман Евсеевич, в своих воспоминаниях вы большое место уделяете рассуждениям об образовании как о способе формирования человека будущего, подчеркиваете необходимость реформирования образования, придания ему новой формы. Большое значение отводите науке, современным природоподобным технологиям. На основании вашего опыта вы пытаетесь предсказать и сформировать принципы развития целых отраслей промышленности будущего. Какой вы видите наноиндустрию России в процессе формирования и внедрения шестого технологического уклада отечественного производства?

Последние 10 лет я пишу книги, так или иначе связанные с нанотехнологиями. Уже более 40 книг написал и работаю над следующей, которая должна появиться в конце этого года в печати. Первая моя книга называется "НаноБиоХимические технологии производства нового поколения волокон текстиля и одежды". По базовому образованию я химик-текстильщик. С появлением нанотехнологий одним из первых применений был как раз текстиль, особенно в коммерческом отношении. Первыми изделиями были текстильные материалы и одежда - гидрофобные, водоотталкивающие, негорючие, пуленепробиваемые материалы. Эта книга посвящена именно этой тематике. Потом пошло все шире, шире, и книга "Бионика" стала одной из самых популярных и любимых читателями. Бионика - это такое направление науки и практики, которое занимается тем, что "подсматривает" у природы различные механизмы и решения разного рода задач и стремится применить их в промышленном производстве на благо человечества. Успешных примеров таких решений огромное количество, сотни из которых вошли в эту книгу. Такие технологии, взятые из природы, называются природоподобными. Самый яркий и известный пример - фотовольтаика. В природе солнечное излучение, попадая на растения, содержащие хлорофилл, преобразуется ими в химическую энергию, производя полезные вещества - сахариды, крахмал, и т.д. По образу и подобию были созданы фотопанели, которые переводят энергию Солнца в электрическую. Вспомним Эйфелеву башню, конструкция которой во многом воспроизводит бедренную кость человека, имеющую пористые стенки. Башня оказалась очень прочной, и в тоже время пластичной, выдерживающей порывы ветра и возникающие вследствие этого вибрации. Теперь эти технологии применяются при строительстве небоскребов. Еще одна книга - "Возрождение природных красителей". Пигменты и красители в природе широко распространены, а человек, в основном, использует синтетические красители, вредные в производстве и применении. Все это имеет отношение к нанотехнологиям. Широко известна и популярна на Западе моя книга "НБИКС - нано био информационные когнитивные и социо-гуманитарные технологии и как они используются для мира и войны", трехтомник "Зеленые природоподобные технологии". Фактически, в этих книгах сформулирована новая идеология отношения к природе и взаимоотношений природы и технологий. Сейчас я активно работаю над книгой "Основы нанотехнологий", которая, как я уже сказал, будет издана в конце года. А есть у меня и книги рассказов, для души. Иногда нужно отвлечься от науки и погрузиться в волшебный мир художественного творчества.

В своих воспоминаниях вы не очень лестно отзываетесь о школьном учителе химии и обстановке на уроках, но всячески всегда подчеркиваете роль образования в формировании человека будущего. Какими вы видите современные уроки химии в школе?

Вопрос интересный и важный. Я ведь недаром начал издавать журнал "НБИКС. Наука. Технологии". Довольно давно, будучи еще молодым преподавателем, я пришел к выводу, что и в школе, и в высших учебных заведениях, и это касается не только химии, преподавать так, как это делается сегодня, нельзя, потому что нельзя изучать, например, химию в отрыве от других естественнонаучных дисциплин и в отрыве от жизни. Этот мой вывод вытекает из фундаментального, неопровержимого закона природы, гласящего, что в природе все со всем взаимосвязано. Нужно лишь видеть, выделять эти многочисленные связи, подчас незаметные поверхностному взгляду. При таком подходе нет учителя химии, учителя физики, биологии, в природе нет кафедр, поскольку все, что происходит в реальной жизни, рукотворной и не рукотворной, и внутри любого, даже маленького, проекта, или большого природного и человеческого, все фундаментальные науки, в нужном порядке, последовательно ли, параллельно ли, связаны друг с другом. А раз так, нужно менять подходы преподавания, не учить селективно каждой из наук, нужно стремиться не к диффе- 
ренцированному, а к интегральному обучению. Нужно прийти к природоподобному образованию. На уроках химии нельзя учить школьников, забывая о физике, не обращаясь к примерам из других наук, и наоборот. Я придерживаюсь принципа междисциплинарности. Его нужно применить даже в начальной, средней, не говоря уже о высшей школе. Это не значит, что нужно отменить преподавание отдельных предметов, необходимо изменить программы обучения так, чтобы в их основе лежали междисциплинарность и демонстрация связей между объектами и явлениями. Это необходимо для того, чтобы у ребенка, и у будущего специалиста складывалась единая картина мироустройства, состоящая из отдельных пазлов, взаимовлияющих друг на друга. Это и есть формирование мозаичного мышления, в отличие от распространенного сейчас клипового. Осознав это, я и основал журнал, чтобы в нем показывать те многочисленные связи между нанобиоинформационными и когнитивными технологиями и объектами. Сам я кондовый химик-технолог, и когда я преподавал студентам старших курсов свои дисциплины, например спецкурс "диффузия и сорбция в процессах чего-то там", то в его рамках рассказывал о диффузии как о явлении, наблюдаемом в разных сферах жизни и описываемом единым математическим аппаратом. Так я пытался воплотить принципы междисциплинарности и межпредметности в своих лекциях и практических занятиях.

Это касается и решения крупных задач. Сегодня для проектных решений набираются специалисты из разных областей - физики, химики, биологи, материаловеды, технологи. Такой коллектив при тесном взаимодействии способен решить сложные задачи за ограниченное время, что очень важно, и выработать их, как правило, на дисциплинарном "пограничьи", на стыках отдельных дисциплин. Это синергетический подход к решению различного рода задач в настоящее время является самым эффективным. Примерами могут служить атомный и космический проекты, и некоторые другие крупные проекты.

Некоторое время назад я организовал чтение лекций для преподавателей средней школы: физиков, математиков, химиков, биологов - и рассказывал им о НБИКС-подходе к обучению. У них горели глаза, им очень нравилось то, о чем я говорил на лекциях. Однако учителя скованы учебными программами и планами, отступать от которых значительно они не могут. Значит, нужно менять и программы, и учебные планы, отражая в них современные тенденции междисциплинарности и межпредметности как в средней, так и в высшей школе.

Как, по вашему мнению, нужно преподавать химию в современных вузах? Считаете ли слияние теоретической базы фундаментальных знаний и практики производств катализатором структурных изменений отечественного образования в области точных наук, в частности, химии и нанотехнологиях?

Очевидно, этот опыт уже есть, в виде практик. В классической системе инженерных практик существуют градации - ознакомительная практика на третьем курсе, производственная, где студенты работают на установках и агрегатах, и преддипломная практика. Но сейчас ее реализовать нельзя, так как частные предприятия студентов берут очень неохотно или вообще не берут, поскольку они там мешают производственному процессу, мешают зарабатывать деньги. Нужно ведь выделить наставника, ответственного за работу со студентами, что-то ему за эту работу заплатить, а это все деньги, которые частник-капиталист выделять не хочет. Даже перспективы привлечения квалифицированных кадров на свое предприятие не играют решающей роли, когда речь идет о сиюминутной выгоде. В будущем, возможно, предприниматели станут мыслить на более далекие перспективы, и такие люди уже есть, но в основной массе "капиталисты без стажа" не жаждут возиться со студентами и терять часть прибыли.

Стратегически, нельзя вырвать только образование, или медицину, или вообще какую-то область знаний и осуществить в ней прорыв, это нужно делать в комплексе, совместными усилиями и реформированием на всех направлениях. Это сложно, и разные направления будут развиваться с разной скоростью, дополняя и влияя друг на друга в процессе реформирования. Нельзя в высшем образовании ограничиться только практикой в лабораториях, необходима связь с производством. Надеюсь, в будущем это станет реальностью.

Существует и второй путь - организация при вузах производственных комплексов, малых предприятий. Попытки такие были, но в целом, как тенденция, у нас в России это не пошло. Брался за основу очень успешный опыт Массачусетского технического института. Если 
возникает проблема или задача, все кафедры, все подразделения МТИ наваливаются на нее, и на предприятиях, расположенных там же, реализуют пилотный, экспериментальный образец, который потом идет в серию и выпускается уже в промышленных масштабах. А чтобы существовала конкуренция, остальные 11 вузов также объединяются для решения этой задачи, и заказчики уже имеют возможность выбирать между достижениями двух команд разработчиков, позволяя комбинировать сильные стороны каждого из проектов, при необходимости.

Судьба научных достижений и разработок очень разнообразна. Иногда успешными бывают достижения, которые ученый считает второстепенными, а его главные идеи и внедрения зачастую не находят должного применения или не получают того развития, на которое рассчитывал исследователь. Какие из своих научных разработок вы считаете самыми успешными, а какие самыми перспективными?

Самым интересным и полезным из того, что я сделал, считаю свою деятельность еще в молодые годы, когда я 23-летним специалистом пришел на шелкоотделочную фабрику Свердлова. После окончания института я попал туда на работу и застал сущий ад. В цехах предприятия было множество красильных машин открытого типа, которые в период так называемой кипы (от слова "кипение") исторгали клубы пара, застилающего все вокруг так, что рабочие, развозившие по цехам реактивы в ручных тележках, не видели друг друга, натыкались, расшибались, получали травмы, не говоря уже о вдыхании колоссального количества вредных веществ, из смены в смену, день за днем, месяц за месяцем, год за годом. Все операции, практически, проводились вручную, включая разведение растворов, дозирование веществ и добавление их в красильные машины.

Увидев все это, я понял, что необходимо срочно обеспечить автоматическое дозирование и механическую доставку веществ к каждой красильной машине. Шел 1958 год. Мною был разработан проект, фактически превративший фабрику в первую в мире химическую стан цию на текстильном производстве. В проекте была создана механическая дозация веществ, предусмотрены реакторы, к которым по рельсам доставлялись реагенты, а впоследствии при помощи насосов готовые вещества закачивались

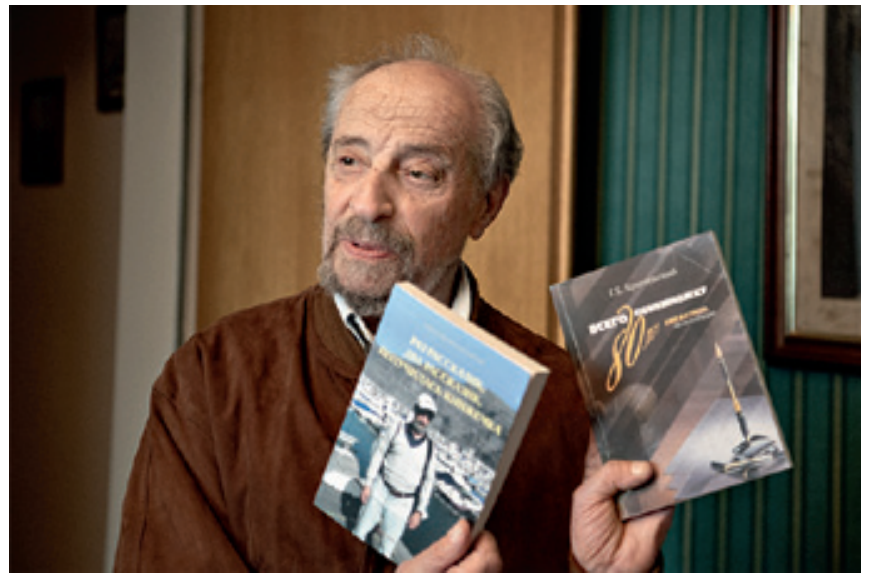

в специальные напорные баки, расположенные сверху, и по прозрачным трубам из силикатного стекла, разведенным по всем цехам, готовые вещества доставлялись к красильным машинам. На переоборудование фабрики ушел год. Наше детище показывали министрам и иностран ным делегациям, и оно просуществовало 25 лет. Здоровье скольких людей было сохранено!

Но за это время в Швейцарии, Японии стали выпускать аналогичные химические стан ции, работающие практически автономно. Безлюдные, четко работающие автономные химические станции - современный уровень и признак шестого технологического уклада. Обидно, что эти годы прошли без существенного прогресса в переоборудовании и автоматизации отечественного химического, да и не только химического производств. Вдвойне обидно, что многие разработки и идеи, возникшие в нашей стране впервые, не получили своего практического применения, а на Западе дельные предложения гораздо чаще внедряются и служат экономикам и, в конечном итоге, повышают качество жизни людей. А мы часто это упускаем!

Отвечая на вторую часть вопроса, расскажу о нашей практической деятельности, в которую мы вкладываем свой интеллект и знания. Около 30 лет назад мы организовали фирму, которой я руковожу и сейчас, специализирующуюся на выпуске продукции медицинского назначения на основе природных полимеров. В основе производства лежит тот же принцип, что и в текстильной печати. Создаются материалы, которые условно можно обобщенно назвать "депо". Как платформа используется текстильный материал, состоящий из ассамблеи волокон, которые, в особенности природные, являются нанообъектами, поскольку имеют 


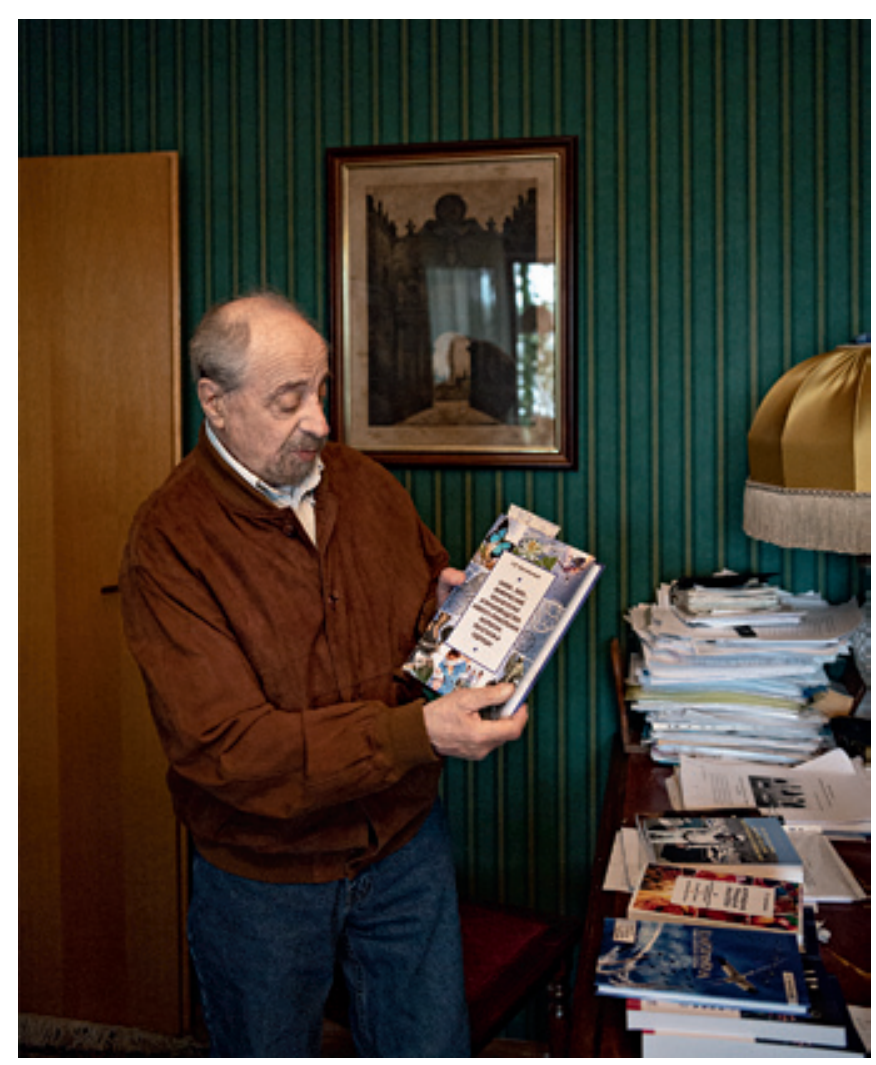

пористую структуру, наиболее развитую в нанометровом диапазоне. Мы изготавливаем из биополимера (альгината натрия, содержащегося в бурых морских водорослях) гидрогель, который мы можем "нагрузить" любым лекарством или биологически активным веществом (БАВ). После этого методом текстильной печати "впрессовываем" БАВ в текстильную ткань. В результате образуется "матрешка", состоящая из тканидепо, гидрогеля и добавок в нем. Принцип действия прост - созданная таким образом повязка, например, наложенная на рану, в результате диффузии вещества-добавки из-за градиента активного вещества проникает вглубь раны, вызывая бактерицидный и лечебный эффекты. Раны быстрее заживляются, а вероятность воспалений в результате попадания патогенных веществ существенно снижается.

Но самое интересное происходит не с наружными, а внутренними ранами, а также при онкологических заболеваниях. В этой области наших исследований и разработок мы получили премию Правительства Российской Федерации.

В этом направлении я бы выделил как напрямую относящуюся к нанотехнологиям область - получение наночастиц благородных и тяжелых металлов с помощью биотехнологий. Альгинат натрия восстанавливает катионы этих металлов до нулевой валентности, а дальше уже они объединяются в кластеры, и основной задачей является уже не допустить разрастание этих кластеров до размеров, превышающих нанотех нологические. Все катионы благородных тяжелых металлов являются прекрасными бактерицидами. Они бьют не только микробы и бактерии, но, подчеркиваю, и вирусы! Главное - научиться направлять воздействие этих наночастиц металлов на патогенные клетки, включая раковые, бактерии и вирусы. Обычно кластеры из наночастиц - оружие очень широкого спектра действия, ему нужно придать селективность. А перед этим - решить задачу их доставки к мишени и высвобождение активного элемента после доставки. Пожалуй, это направление можно выделить как самое важное, глубокое с научной точки зрения и наиболее перспективное. Мы верим, что за подобными технологиями будущее.

Какими вы видите перспективы наномедицины и наноонкологии? Будет ли использован опыт борьбы с COVID-19 для усовершенствования технологий и методов борьбы с раком?

Безусловно. И путь решения этих задач уже вырисовывается. Фактически, имея результаты воздействия на раковые клетки наших "матрешек", отработав целевую доставку лечебного вещества к раковым клеткам, уже можно запускать лечение, в том числе отработав воздействие и непосредственно на вирусы. Основная проблема пока состоит в том, чтобы научиться создавать "матрешки" с наперед заданной селективностью, перейти от широкого спектра действия к узкому, направленному непосредственно на патогенные клетки. Фигурально выражаясь, нужно перейти от артиллерии к снайперской дуэли с раковыми заболеваниями.

Перспективно ли промышленное получение наночастиц металлов с помощью микроорганизмов и в каких областях возможно применение полученных таким образом нановеществ? В первую очередь, нужно иметь хорошую микробиологическую промышленность. Однако, на мой взгляд, гораздо проще для получения наноразмерных частиц использовать природные, содержащиеся в растениях, метаболиты. Крахмал, альгинат натрия, полисахариды, отходы цитрусовых, зерновой промышленности, даже пищевые кухонные отходы можно использовать для получения наночастиц тяжелых и благородных металлов. Все природные 
вещества являются хорошими биовосстановителями. Возьмем альгинат натрия, загустим его, получим коллоид, введем туда нитрат серебра $\mathrm{AgNO}_{3}$, или соли золота, или водорастворимые соли меди, и при небольшом нагревании, при температуре слегка выше комнатной, начнет происходить реакция образования наночастиц. Через час или несколько часов, в зависимости от металла, синтез завершится. Останется упаковать полученный гель в тубы, провести гамма стерилизацию, и исходный материал готов. Материалы с наночастицами благородных и тяжелых металлов могут быть отличным товаром на мировом рынке, потребность в них колоссальная, ими можно торговать, рынок такой продукции насчитывает миллиарды долларов! А параллельно с продажами, используя вырученные деньги, создавать отечественного потребителя нановеществ, развивать собственную наноиндустрию.

Что ждет Нанотехнологическое общество России в ближайшей и среднесрочной перспективе?

Сложно ответить на этот вопрос, не раскрыв понятие "нанотехнологии". По сути, нанотехнологов никогда же не было. Не было таких специальностей в вузах, да и сейчас не во многих есть. Кто же занимается нанотехнологиями? Какие специалисты? Физики и химики, математики, материаловеды, в большинстве своем. Но у них существуют два подхода к производству нанообъектов - принцип деления чего-то до уровня наноразмеров и принцип прямого синтеза нанообъектов. Иногда специалисты, придерживающиеся этих подходов, не могут понять друг друга, настолько в разных парадигмах они работают. Мы же объединяем их в одно научное общество, стремясь сформировать индустриальную платформу, состоящую из химической промышленности, машиностроения, микро- и наноэлектроники и т.д. Индустриальная платформа и будет крупнейшим потребителем продукции нанотехнологий, и к ее созданию нужно стремиться. Это одна из наиболее важных задач нашего общества, помимо популяризации науки и достижений нанотехнологий и наноиндустрии. Наше Нанотехнологическое общество России - общественная организация, и мы не всесильны, особенно в современных условиях.

Могут ли все составляющие НБИКС (NBICS) технологий развиваться с одинаковой скоростью?
Взаимовлияние их - тормоз или ускоритель развития шестого технологического уклада? Нет, конечно. Они развиваются и взаимодействуют друг с другом, подталкивая друг друга, промышленность и образование. Главное - создать условия для успешного развития, и постоянно иметь ввиду, что нужно развивать технологии двойного назначения. Сейчас мы находимся не в каком-то определенном промыш ленном укладе, в России смесь укладов, образно говоря, в данный исторический момент мы застряли в определенном "межукладье". И выход из этого - туннелирование, скачкообразный переход из уклада $\mathrm{N}$ сразу в $\mathrm{N}+2$. Нужно развивать целые отрасли промышленности, провести новую индустриализацию страны на уровнях самых современных технологических укладов. Например, можно производить наночастицы для композитов. Мы же живем в век новых материалов, которые постоянно и быстро вытесняют многие традиционные материалы, вспомним хотя бы современные самолеты. Они же почти полностью состоят из композитов, как и транспорт, например. Начинать новый виток развития следует с промышленности, нужно развить хотя бы связку нано-, био-, инфотехнологий, в первую очередь, сформировать с ее помощью платформу будущего развития.

\section{Что бы вы хотели сказать нашим читателям?} Я бы хотел обратиться к молодежи. Это очень интересное, перспективное направление деятельности, прибыльное, имеющее колоссальный потенциал развития как в нашей стране, так и за рубежом. Давайте развивать нанотехнологии и наноиндустрию в России. Это, помимо прочего, и очень гуманная, благородная сфера деятельности, она связана с медициной, то есть напрямую со здоровьем людей. Нанотерапия, нанодиагностика, наноонкология - в настоящее время самые емкие направления развития нанотехнологий. Ситуация меняется, и, возможно, именно сейчас наступает тот самый, поворотный, момент, когда возможен синергетический прорыв, тот самый туннельный скачок в новое технологическое будущее. А это будущее нужно формировать прямо сейчас, иначе настоящее растянется на неопределенное время. Работа над будущим происходит в настоящем, а настоящее - суть наше бытие, и его творческое преобразование и составляет смысл того, что мы называем жизнью.

Спасибо за интересную беседу! 